\title{
A POSSIBILIDADE DE DESENVOLVER PESQUISAS NO CAMPO JURÍDICO VALENDO-SE DA METODOLOGIA DE ABORDAGEM QUALITATIVA
}

\section{THE POSSIBILITY OF DEVELOPING RESEARCHES IN THE LEGAL FIELD MAKING USE OF THE QUALITATIVE APPROACH METHODOLOGY}

\author{
${ }^{1}$ Adriana Ferreira Serafim de Oliveira \\ ${ }^{2}$ Jorge Luis Mialhe
}

\section{RESUMO}

Este artigo, através da pesquisa dedutiva, discute a possibilidade de pesquisar no campo jurídico através da metodologia de abordagem qualitativa utilizada nas pesquisas em ciências humanas. O norte para este estudo foi dado pela metodologia de abordagem qualitativa na exploração do conteúdo da bibliografia interdisciplinar eleita nas áreas de direito e educação, considerando o objeto de estudo a conexão dos objetos de pesquisa nas áreas jurídica e de educação. A educação, nas ciências humanas, utiliza dessa abordagem para investigar fatos por meio de pesquisas documentais ou de campo e a mesma metodologia pode ser aplicada no campo do direito.

Palavras-chave: Ciência do direito, Metodologia jurídica, Pesquisa qualitativa

\begin{abstract}
This article, through the deductive research, discusses the possibility to research in the field of legal sciences through the qualitative methodology used in the researches in Human Sciences. The north for this study was given by the qualitative methodology to the exploration of the content of the bibliography interdisciplinary elected in Law and Education areas, considering the object of the study the connection of the objects of the research in these areas. Education, in Human Sciences, uses this approach to investigate facts through documentary or field research and the same methodology can be applied in the Law area.
\end{abstract}

Keywords: Science of law, Legal methodology, Qualitative research

\footnotetext{
${ }^{1}$ Doutoranda em Educacao na Universidade Estadual Paulista Júlio de Mesquita Filho - UNESP, São Paulo - SP (Brasil). Professora da Universidade Metodista de Piracicaba - UNIMEP, São Paulo (Brasil).

E-mail: adrianaferserol@ hotmail.com

${ }^{2}$ Doutor em História Social pela Universidade de São Paulo - USP (Brasil). Professor Universidade Estadual Paulista Júlio de Mesquita Filho - UNESP, São Paulo - SP (Brasil)

E-mail: profmialhe@ hotmail.com
} 


\section{INTRODUÇÃO}

O presente artigo, através da pesquisa dedutiva, de técnica histórica, e qualitativa, objetiva investigar a possibilidade de desenvolver pesquisas no campo jurídico valendo-se da metodologia de abordagem qualitativa, tendo em vista que os objetos de pesquisa das ciências humanas e das ciências jurídicas equivalem-se, ou seja, os seres humanos e as ações desses, as quais geram fatos que podem ser tutelados juridicamente.

Para tanto, a pesquisa trata da abordagem qualitativa nas ciências humanas e sociais aplicadas, que permite a produção do conhecimento através de uma amostra e abstrair do conteúdo em estudo, valores, crenças, hábitos, atitudes, representações e opiniões, o que é próprio dos seres humanos. Ainda, adequa-se a aprofundar a complexidade de fatos e processos particulares e específicos tanto para indivíduos como para grupos sociais. (PAULILO, 1999, p.135-136).

A investigação sobre a possibilidade de desenvolver pesquisas no campo jurídico, valendo-se da metodologia de abordagem qualitativa, teve como reflexão inicial as várias possibilidades ou métodos de produção do conhecimento científico.

A produção do conhecimento científico passou por transformações do mesmo modo que transcorreu a história da humanidade, permitindo que novos métodos fossem eleitos para consagrar um conhecimento produzido por uma pesquisa como ciência.

Entre os séculos XVI e XVIII surgiram as ciências humanas analisadas pelo filósofo e pedagogo alemão Wilhelm Dilthey (1833-1911). Segundo Scocuglia (2002), Dilthey estabelece diferenças entre a lógica do conhecimento nas ciências naturais e nas ciências humanas. Ele buscava os fundamentos filosóficos e epistemológicos de uma forma de conhecimento científico alternativo ao conhecimento positivista e naturalista, sendo este obtido com a pesquisa através de um método nas ciências naturais. Dilthey afirmava não ser possível no campo das "ciências do espírito", como se referia às ciências humanas ${ }^{1}$, falar em leis gerais, pois o conceito dessas ciências implicava pensar em termos de "motivos" e de "desejos" para explicar situações de mudança. (SCOCUGLIA, 2002, p. 250-251).

1 Entre elas, destacam-se "a História, Economia, as Ciências do Direito e do Estado, Ciências da Religião, o estudo da literatura e da poesia, da arte e da música, da concepção filosófica do mundo e dos sistemas, e finalmente da psicologia”. (AMARAL, 2010, p.16) 
Com os estudos de Scocuglia (2002) a respeito das teses sobre ciências humanas de Dilthey, abstrai-se que a motivação, o anseio e o desejo são características emocionais próprias dos seres humanos por demandarem racionalidade, portanto os seres humanos são o objeto de estudo de sua própria ciência e passíveis de mudanças.

Nas ciências humanas o próprio sujeito é também o objeto para ser conhecido. (GEWANSDZNAJDE; MAZZOTTI, 1999, p. 5). Nas ciências jurídicas, os fatos produzidos pelos seres humanos são passíveis de estudos científicos. (FERRAZ JUNIOR, 1977 , p. 42).

A pesquisa para produzir conhecimento nas ciências humanas considera os seres humanos como objeto de estudo e no campo da ciência jurídica, o objeto de estudo trata dos fatos produzidos pela ação desses indivíduos, portanto pretende-se demonstrar a conexão entre os objetos de pesquisa das ciências citadas e a possibilidade de aplicação da mesma metodologia científica.

A ciência do direito demonstra que os princípios estão para a teoria e metodologia da ciência, a partir de uma concepção epistemológica. Para a dogmática analítica, todo e qualquer comportamento humano é passível de ser reduzido a uma norma, ao seu cumprimento ou descumprimento, sendo juridicamente irrelevante eventual conduta fora desse enquadramento. Isso reflete a concepção da norma tida como regra. (FERRAZ JUNIOR, 1977, p. 57).

Com as considerações de Ferraz Júnior (1977) observa-se que o comportamento em estudo é do ser humano, portanto, há peculiaridade entre os objetos de estudo das ciências humanas (o ser humano) e das ciências jurídica ou ciência do direito (os fatos, comportamentos produzidos pelo ser humano).

\section{CONSIDERAÇÕES SOBRE A PESQUISA CIENTÍFICA NO CAMPO DA EDUCAÇÃO E NO CAMPO DAS CIÊNCIAS JURÍDICAS}

Os estudos dos autores Gewansdznajde; Mazzotti (1999) consideram que não é possível sustentar uma visão de ciência objetiva, neutra, aquém da linha cronológica histórica, a qual seja capaz de formular leis gerais sobre o funcionamento da natureza. No mesmo sentido, os autores sustentam que o método utilizado pelas ciências sociais e humanas deriva do modelo das ciências naturais, embora essas pesquisas tratem dos fenômenos humanos e sociais. (GEWANSDZNAJDE; MAZZOTTI, 1999, p. 3; 6). 
A pesquisa em questão guarda estudos das obras de autores previamente definidos e a serem consultados à posteriori, os quais são adeptos da teoria crítica, tendo em vista que de acordo com as considerações dos mesmos autores, essa teoria busca a transformação da sociedade como também a emancipação do homem, o sujeito e o objeto são elementos integrados e coparticipantes do processo de pesquisa e o julgamento de valor do pesquisador é considerado parte essencial do processo de pesquisa. (Idem, 1999, p. 119).

Conforme os autores citados, o método utilizado tanto nas ciências sociais como humanas deriva do modelo das ciências naturais para fenômenos diferentes. Considerando que a sociedade é formada por seres humanos os objetos de pesquisa guardam conexão, permitindo assim a escolha da mesma abordagem metodológica para produção de conhecimento, neste caso, a qualitativa.

A opção da pesquisa pela teoria crítica, a qual é uma das oposições ao paradigma do positivismo, encontra esteio na possibilidade de que a pesquisa poderá partir do pressuposto que o ser humano age de acordo com os sentimentos e valores afetos a si e ao seu entorno, permitindo que os pesquisadores de culturas e modos de vida aprofundem-se nos métodos qualitativos, enquanto que os seguidores do paradigma positivista melhor se enquadrem nos métodos quantitativos. (GEWANSDZNAJDE; MAZZOTTI, 1999, p. 120-123).

Gatti (2002) corrobora no mesmo sentido ao aduzir que o conhecimento obtido pela pesquisa é situado, vinculado a critérios de escolha e interpretação de dados pelo pesquisador, qualquer que seja a natureza dos dados em estudo. (GATTI, 2002, p. 12).

As afirmações dos autores citados quanto à pesquisa admitem a influência do pesquisador na construção dos dados tendo em vista o olhar que irá dirigir aos dados colhidos em documentos, legislações e em campo de acordo com o referencial teórico adotado e com o ângulo de abordagem escolhido.

Assim, a pesquisa em educação tem natureza interdisciplinar por congregar profissionais das diversas áreas das ciências sociais, o que reflete aspectos básicos pertinentes a todas essas áreas. (GEWANSDZNAJDE; MAZZOTTI, 1999, p. 122).

Gatti (2002) explica que a pesquisa educacional compreende diversas questões de diferentes conotações, as quais estão relacionadas de modo complexo ao desenvolvimento das pessoas e das sociedades e desse modo abrange aspectos filosóficos, sociológicos, psicológicos, políticos, históricos, entre outros. (GATTI, 2002, p. 13).

Dilthey (2010) no seu ensaio "Sobre a possibilidade de uma ciência pedagógica de validade universal", publicado em 1888, concluiu que: 
O objetivo da educação só pode ser derivado do objetivo da vida, mas este não pode ser determinado de modo universalmente válido pela ética. A própria história da moral nos ensina isso. O ser humano só descobre o que ele é e o que quer no decorrer do desenvolvimento de seu ser através dos milênios, e nunca de modo definitivo, nunca por conceitos universalmente válidos, mas sempre apenas por meio de experiências vivas que provêm das profundezas de todo o seu ser. Toda e qualquer fórmula de conteúdo sobre o fim último da vida humana revelou-se historicamente condicionada. Até hoje, nenhum sistema moral conseguiu conquistar reconhecimento universal. (DILTHEY, 2010, p.464465).

Nesse sentido, na ausência de "conceitos universalmente válidos" e frente a complexidade da pós-modernidade, torna-se cada vez mais necessário uma abordagem interdisciplinar, com a intenção de verificar as várias dimensões dos objetos de investigação.

Para Lyotard (2011) o pós-modernismo caracteriza-se pela "morte dos centros" e pela incredulidade em relação às meta-narrativas". O primeiro elemento, ensina Cardoso (2011), questiona o locus "a partir dos quais se afirmariam diversas posturas (...) arbitrárias e passageiras, articuladoras de interesses que socialmente não são universais: são sempre particulares, relativos a grupos restritos e socialmente hierarquizados de poder". O segundo elemento, de caráter niilista e relativismo absoluto, indica que "qualquer metadiscurso, qualquer teoria global, tornou-se impossível de sustentar devido ao colapso na crença nos valores de todo tipo e em sua hierarquização como sendo universais". Assim, "o conhecimento se reduz a processos de semiose e interpretação (hermenêutica) impossíveis de ser hierarquizados de algum modo que possa pretender ao consenso". (CARDOSO, 2011, p.15).

Com relação ao estudo de culturas e modos de vida possíveis tanto no âmbito das ciências humanas como nas ciências sociais aplicadas, Herrera Flores (2013), demonstra em seus estudos no campo jurídico que quanto aos direitos humanos, os mesmos não são universais, pois são construções culturais de cada sociedade, a qual clama o direito positivo, materializado nas leis de acordo com suas necessidades, o que chamamos de fato social.

A pesquisa no campo do Direito no Brasil sofre críticas de estudiosos como Monebhurrun e Varella (2013), pois enquanto algumas teses de doutorado contribuem para a formação potencial de professores e pesquisadores, outros trabalhos, apresentados como teses, buscam apenas a obtenção do título de doutor por mera vanitas dos seus autores, sem vocação para a docência. 
Corroborando o entendimento de Monebhurrun e Varella (2013), entende-se a tese como um trabalho de pesquisa e não um tratado ou um manual, com a atualização do estado da arte. Qualitativamente, a tese deve "trazer exemplos reais do seu tema, sobretudo quando não se trata de uma tese meramente filosófica", propondo-se "a analisar um determinado instituto jurídico e o seu reconhecimento ou não pela jurisprudência". Os autores consideram ser difícil encontrar uma diretriz metodológica uniforme ao examinar as teses de doutorado em Direito no Brasil. Entretanto, é possível afirmar que não há um guia típico e intrinsecamente brasileiro sobre como conduzir uma tese, ou seja, não há um modelo

predefinido a seguir. Assim, cada pesquisa científica no campo jurídico obedece aos critérios definidos pelo autor e, certamente, pelo orientador. (MONEBHURRUN; VARELLA, 2013, p. 430-435).

As considerações dos autores supracitados permitem que defendamos a introdução da metodologia de abordagem qualitativa nos campos de pesquisa jurídica pelas possibilidades de estudo que essa metodologia propõe, fazendo uso de instrumentos, tais como a pesquisa de campo por meio de entrevista e grupo focal, de onde surgirão dados possíveis de interpretação pela técnica da análise de conteúdo, o que dará ao pesquisador uma amostra da realidade pesquisada, da qual será possível fazer inferências e deduções com base no referencial teórico adotado para produção do conhecimento, o qual pode propiciar uma aproximação tanto humana como técnica da inovação ou solução proposta para o objeto de pesquisa estudado.

\section{A PESQUISA DE ABORDAGEM QUALITATIVA E OS PROCEDIMENTOS POSSÍVEIS NESSA METODOLOGIA}

A produção de conhecimento por meio da pesquisa de abordagem qualitativa caracteriza-se pelo contato direto do pesquisador com a realidade, o que oferece a possibilidade de documentar o não documentável, tendo em vista o caráter investigativo de percepção da realidade. (LUDKE, ANDRÉ, 1986, p. 11-13).

A escolha pela abordagem qualitativa permite a identificação dos significados culturais presentes nos diferentes grupos de participantes.

A título exemplificativo, quando se investiga os níveis de violência doméstica dentro das grandezas tempo e espaço, tem-se um período a ser analisado dentro de uma 
região geográfica determinada. Admitindo, hipoteticamente, o período de cinco anos e as cinco regiões brasileiras, o pesquisador entrevistará duzentas mulheres divididas em cidades dessas regiões, culturalmente diferentes. Uma das condições para ser participante da pesquisa é, no período assinalado, ter sido vítima de violência doméstica e ter recebido atendimento pelo poder público, inclusive acolhimento em casas abrigo. Com esse procedimento, fica determinada a amostra.

A entrevista das participantes conterá questões visando colher dados que possibilite entender a eficácia das políticas públicas de cada região quanto ao atendimento das vitimadas. As respostas das entrevistas deverão ser transcritas e essa transcrição fornecerá dados, os quais serão analisados e interpretados conforme o referencial teórico escolhido pelo pesquisador.

Dessa maneira o conhecimento científico produzido por meio da abordagem qualitativa, possibilitará a compreensão de quais políticas públicas funcionam, quais se mostraram ineficazes e quais são as necessidades de cada região quanto à intervenção estatal.

Ainda na forma de pensar dessas vítimas, quando entrevistadas em pesquisa de campo, o pesquisador poderá na análise de conteúdo verificar as semelhanças e as diferenças nos discursos das participantes da pesquisa.

No exemplo citado, os dados obtidos na pesquisa poderão propiciar análises dos conteúdos de acordo com o direito penal e políticas públicas sociais. Entretanto, a amostra da realidade poderá beneficiar qualquer área jurídica com a produção de conhecimento.

Conforme assinala Aguirre Báztan (1995), a metodologia qualitativa é um processo e um produto, pois permite o estudo de inúmeras subjetividades dentro de um grupo em um trabalho de campo e constitui-se no relatório de todo o processo compreendido pelo pesquisador. (AGUIRRE BÁZTAN, 1995, p. 5-20).

Assim, a pesquisa qualitativa possibilita a flexibilidade e a interação do pesquisador com o participante da pesquisa, permitindo a adaptação dos instrumentos utilizados como entrevistas, grupos focais, a realização de pré-teste das entrevistas, entre outros.

Para a concretização dos objetivos, a pesquisa por meio da abordagem qualitativa oferece um leque de possibilidades, as quais são chamadas de procedimentos. A revisão da bibliografia pertinente referente às temáticas eleitas buscando a concepção do objeto 
de estudo nessas bibliografias, a pesquisa de campo, as entrevistas, os sujeitos participantes da pesquisa, a descrição do local da pesquisa de campo, entre outros, são alguns exemplos.

Para traçar o perfil dos sujeitos em estudo, pode-se aplicar um questionário que tem por objetivo a caracterização social e econômica do grupo a ser investigado, obtendo dessa maneira uma amostra da realidade a ser analisada, portando, enquadrando essa amostra em um tempo e espaço, o que chamamos de tempo histórico em um determinado local.

O roteiro previsto para o questionário pode ser descrito como: idade; estado civil, escolaridade, profissão, moradia, número de filhos, idade dos filhos, religião, renda mensal familiar, seguindo-se das questões específicas com o objeto de estudo pesquisado.

Uma das possibilidades é a realização de entrevistas de acordo com os ensinamentos de Manzini (2003), autor que explica a entrevista como um processo de interação social e os dados obtidos são de natureza social também, o que precisa ser levado em consideração na interpretação dos resultados.

Por meio da entrevista alcança-se o estudo do relato dos fatos e não os fatos propriamente ditos, difíceis ou impossíveis de serem estudados quando de sua ocorrência. As entrevistas podem ser estruturadas, com questionamentos prontos e não modificáveis durante o processo de coleta de dados ou semiestruturadas, com questionamentos semelhantes a uma espinha dorsal e com questões que podem ser inseridas durante o processo de coleta de dados.

A entrevista semiestruturada também conhecida como semiaberta, de acordo com os ensinamentos de Triviños (1987) e Manzini (2003), têm como características os questionamentos básicos que são apoiados em teorias e hipóteses que se relacionam ao tema da pesquisa, favorecendo a descrição dos fenômenos sociais, sua explicação e a compreensão da totalidade. Possuem questionamentos básicos e permitem enxertos de novas questões no mesmo tema de acordo com o fluir das respostas do participante ao pesquisador. (TRIVINOS,1987, p. 152).

O planejamento das entrevistas deve levar em consideração a posição do pesquisador na coleta de dados, como por exemplo, a ciência da influência do pesquisador na produção do discurso do entrevistado. Para tanto, o pesquisador deverá atentar para não destoar na vestimenta quanto ao entrevistado, ser amistoso, não se colocar em posição de superioridade e propiciar um ambiente para a fluência do relato dos fatos. 
$\mathrm{O}$ roteiro previsto para a entrevista deve ser elaborado numa linguagem clara e acessível para o participante da pesquisa entender o que se pergunta e o número razoável de questões deve estar por volta de 14-18 questões, as quais devem ter relação direta com o objetivo do estudo, entretanto esse número pode variar de acordo com a pesquisa. (MANZINI, 2004, p.58-59)

Para o procedimento denominado entrevista ocorrer é necessário que o "Comitê de ética e pesquisa em ou com seres humanos", da instituição ou universidade a que os pesquisadores estejam ligados, defira um termo denominado "TCLE - termo de consentimento livre e esclarecido", o qual tem o condão de demonstrar o rigor científico do pesquisador quanto ao objeto da pesquisa.

Sabendo que o ser humano na sociedade como objeto de estudo é passível de mudanças e transformações de acordo com suas convicções ou cultura em que vive, referido Comitê segue normas, as quais cuidam de resguardar a dignidade humana, pois a pesquisa não pode ferir os direitos fundamentais dos seres humanos e nem causar qualquer dano ao participante da pesquisa.

As entrevistas deverão ocorrer individualmente, diferentemente do questionário, o qual poderá ser aplicado coletivamente. O questionário geralmente é aplicado para obter a situação socioeconômica do grupo pesquisado. Após o consentimento da participante podem ser filmadas, gravadas e posteriormente transcritas as entrevistas, preservando-se a identidade dos participantes.

Ao finalizar os estudos bibliográficos e as pesquisas de campo, os dados deverão ser organizados visando identificar tendências e padrões relevantes. A técnica empregada para o estudo dos documentos e dos depoimentos das entrevistadas chama-se análise de conteúdo. (BARDIN, 2009, p.118-121).

Segundo a autora, a análise de conteúdo é importante para compreender e inferir novos conhecimentos a partir dos relatos dos diferentes sujeitos. Esta estratégia busca compreender o conteúdo manifesto e ou latente e significações explícitas e ou ocultas contidas nos dados obtidos. Este tipo de análise considera a mensagem escrita ou dita.

A análise de conteúdo pode ser comparada à arte da "desocultação", a "atração" por desvelar o escondido, o não aparente, o potencial inédito (do não dito), retido por qualquer mensagem. (BARDIN, 2009, p.119-121).

A mensagem do que está escrito refere-se ao que está no corpus documental e o que está dito refere-se ao que está na mensagem dos participantes. Como decorrência desta 
metodologia acontecerá uma passagem explícita e controlada da descrição à interpretação utilizando como referencial de análise um quadro teórico sobre o qual o estudo será construído e aplicando os ensinamentos de Bardin (2009) serão criadas unidades de registro.

Por exemplo, um tema que seja recorrente nas entrevistas, ou seja, ausente para entender após a enumeração da frequência dessa presença e ou ausência qual a inferência a ser descrita. Equivale dizer que os dados coletados serão classificados e categorizados em diferentes blocos temáticos definidos a partir do discurso dos participantes e da revisão bibliográfica da área. Serão identificadas as dimensões frequentes ou enfatizadas em cada um desses blocos, como também as diferenças encontradas. (BARDIN, 2009, p. 122126).

A análise de conteúdo deve buscar cumprir as regras de exaustividade (ter em conta todos os elementos do corpus documental e da pesquisa de campo), representatividade (observar com relação aos dados obtidos quão representativos ou não são do que quer se estudar), homogeneidade (todas as entrevistas devem referir-se ao mesmo tema) e pertinência (os documentos e entrevistas devem corresponder ao objetivo da análise).

Os resultados deverão ser tratados de maneira a serem significativos e válidos em um quadro de resultados que coloca em relevo as informações oferecidas pela análise. Então, os dados obtidos serão interpretados de acordo com o referencial teórico adotado.

\section{A CONEXÃO dOS OBJETIVOS DE PESQUISA E A UTILIZAÇÃO DA METODOLOGIA DE ABORDAGEM QUALITATIVA}

As pesquisas no campo das ciências jurídicas se valem de áreas interdisciplinares, tendo como modelo os fatos sociais que se desenrolam no seio das sociedades. Há possibilidade da utilização da pesquisa de abordagem qualitativa, quantitativa ou uma mistura de ambas, conhecida como quali-quanti.

A aplicação da metodologia científica na área jurídica trata de um ponto polêmico da pesquisa científica pela dificuldade dos pesquisadores em transpor, validar e terem validados por outros pesquisadores, conhecimentos da área jurídica para outras áreas, e vice-versa.

A pesquisa científica interdisciplinar fornece respostas que a pesquisa unidisciplinar não alcança por ter o referencial de uma única área para responder os 
questionamentos propostos pelo recorte do objeto de pesquisa. É pouco compreendida e confusamente aplicada. A interdisciplinaridade implica na transferência de conhecimento de uma área para outra. Assim, distingue-se da multidisciplinariedade que implica na reunião de áreas de conhecimento.

Segundo Jacques Ellul (1980) técnica designa arte ou ofício e advém do grego techne ( $\tau \dot{\varepsilon} \chi v \eta)$. A ciência sofreu transformações ao longo da história e continuará mudando de acordo com o avanço da técnica. Ellul refere-se aos saltos da ciência com o advento da revolução industrial e o desenvolvimento do capitalismo de produção fabril. Com a invenção da máquina, aparece o vocábulo tecnologia, como sendo o estudo e processo de construção e utilização das máquinas (ELLUL, 1980, p. 24-25).

A técnica, dessa forma, surge e se desenvolve num contexto histórico individualizado e atomizado passando a ser um fenômeno que busca a exatidão e a perfeição se distanciando do elemento humano, ganhando cada vez mais autonomia, revestindo-se de racionalidade e artificialidade, codificada por símbolos. (ELLUL, 1968, p. 144-145).

O entendimento separado de uma ciência, valendo-se apenas da técnica, traz prejuízo à própria produção do conhecimento, que se fragmenta. Por este motivo a interdisciplinariedade é um caminho para o entendimento global de um fenômeno no campo das ciências jurídicas. A realização da pesquisa através da metodologia qualitativa permite através do destaque de uma amostra do fenômeno que se deseja pesquisar, produzir conhecimento científico sobre o fenômeno equivalente a contexto por inteiro.

Exemplificando, para estudar o fenômeno violência escolar em um bairro de um município, pode-se destacar alguns alunos de cada escola do bairro em questão para serem entrevistados. Os alunos participantes da pesquisa são a amostra da realidade escolar naquele bairro. A partir de então a metodologia qualitativa permite por meio da análise de conteúdo e das inferências feitas nos dados colhidos, dar a conhecer, revelar o escondido, dos porquês da violência escolar nas escolas do bairro em destaque. 


\section{AS PESQUISAS QUALITATIVAS NA ÁREA JURÍDICA DISPONÍVEIS NO PORTAL DE PERIÓDICOS CAPES E NA BASE DE PERIÓDICOS SCIELO}

As pesquisas qualitativas na área jurídica são, ainda, muito restritas como demonstram os resultados de um levantamento realizado no portal de periódicos CAPES e na base de periódicos Scielo - Scientific Electronic Library Online.

Realizou-se uma prospecção acerca do uso da metodologia de abordagem qualitativa em pesquisas jurídicas, na qual foram utilizadas as keywords "qualitative research" e "law", acessadas no portal de periódicos CAPES e as palavras-chave "direito" e "pesquisa qualitativa", pesquisadas na base de periódicos a Scielo.

Os resultados obtidos foram bastante limitados. No portal de periódicos CAPES, foram encontrados quatro artigos, sendo apenas um deles relativo ao tema da pesquisa: Motorcyclists' reactions to safety helmet law: a qualitative study, de Fereshteh Zamani Alavijeh; Fazlollah Ahmadi e Shahrzad Hejazi Bazargan. Este artigo foi publicado em um periódico da área de saúde pública e trata da "negligência epidêmica" dos motociclistas iranianos que se recusam a respeitar a lei que exige o uso de capacete no trânsito e as suas consequências.

Já na base de periódicos Scielo, foram encontrados 46 artigos, sendo cinco deles vinculados ao tema da pesquisa qualitativa apenas na área jurídica. Os demais artigos, na sua imensa maioria inter e transdisciplinares, foram publicados em periódicos na área de saúde pública.

Os cinco artigos encontrados na base de periódicos Scielo foram:

O estatuto jurídico das águas no Brasil, de Fernando Mussa Abujamra Aith e Renata Rothbarth. Resumo:

Para construir o desenho do Estatuto Jurídico das Águas no Brasil, foram pesquisadas e analisadas as normas jurídicas internacionais e nacionais que tratam direta ou indiretamente das águas, com enfoque na identificação, nessas normas, dos seguintes elementos: i) grau de reconhecimento jurídico formal da água como um direito humano fundamental no Brasil e no direito internacional; ii) regime constitucional das águas no Brasil; iii) natureza jurídica das águas no direito interno e; iv) garantias jurídicas para a proteção do direito à água. A pesquisa, qualitativa,

foi realizada nas páginas oficiais do governo brasileiro e da Organização das Nações Unidas, e as normas selecionadas e analisadas foram àquelas vigentes e que apresentam conteúdo relevante para a construção teórica do Estado Jurídico das Águas. (grifo nosso); 


\title{
Derecho a la autodeterminación de los pueblos indígenas en el
} ordenamiento jurídico colombiano, de Sorily Figuera Vargas e Andrea Ariza Lascarro.

Resumo:

\begin{abstract}
El Derecho Internacional de los Derechos Humanos ha sufrido en los últimos veinte años una transformación y renovación en lo que atañe a los indígenas, adjudicándoles a éstos una serie de prerrogativas, como un estatus propio dentro del Derecho Internacional Público, bajo la categoría de pueblos. De esta manera, las implicaciones de ostentar la condición y el reconocimiento como pueblo conducen necesariamente a la autodeterminación como derecho imputable a estos grupos humanos. Ahora bien, pese a este reconocimiento, actualmente muchos pueblos indígenas continúan siendo marginados dentro de los Estados latinoamericanos. En algunos países de la región, por ejemplo, se continúan otorgando cuantiosas concesiones a transnacionales dentro de los territorios de sus pueblos indígenas, sin realizar el idóneo procedimiento de Consulta Previa que contemplan las legislaciones internacionales y nacionales, desconociéndose, así, el derecho a la autodeterminación de estos colectivos. Frente a esta problemática, se estimó pertinente analizar hasta quépunto el derecho a la libre determinación de los pueblos indígenas está siendo protegido dentro del Estado colombiano, para lo cual se desarrolló una investigación cualitativa con análisis documental. En tal contexto, este estudio arrojó como conclusión fundamental la inexistencia de una verdadera regulación que garantice eficazmente la autodeterminación de los pueblos indígenas en Colombia. Y resulta cuestionable, incluso, la existencia de un verdadero pluralismo jurídico dentro de este Estado, en los términos a los que parece referirse el Art. 1 de la Constitución Política de 1991. (grifo nosso);
\end{abstract}

Princípio da eficiência econômico-social no direito brasileiro: a tomada de decisão normativo-judicial, de Everton das Neves Gonçalves e Joana Stelzer. Resumo:

\begin{abstract}
O Direito disciplina, para além da moral, a fenomenologia social exigindo olhar multidisciplinar e interdisciplinar; ainda, identificando, na formalidade legal, a realidade social. A Ciência Econômica confere eficácia ao Direito, relevadas, no cálculo econométrico próprio da eficiente tomada de decisão normativo-jurídica, variáveis próprias de inclusão social. Este artigo objetiva identificar o Princípio da Eficiência Econômico-Social (PEES); justificando-se pela necessidade de delimitar categoria teórica distinta de interação econômico-jurídica. Trata-se de pesquisa qualitativa exploratória, de procedimento monográfico, de abordagem dedutiva e técnica de pesquisa bibliográfica. $\mathrm{O}$ artigo conclui pela criação e aplicação de Direito, socialmente inclusor; progressista, eficaz e eficiente; atento ao contexto econômico, político e jurídico tal como preconizado pelo Princípio da Eficiência Econômico Social. (grifo nosso);
\end{abstract}

El concepto de víctima al interior de tribunales penales internacionales, de Daniel Ricardo Vargas Díaz. Resumo: 
El objetivo principal del presente estudio se enfoca en analizar las similitudes y divergencias que se presentan al interior de los tribunales penales internacionales respecto al concepto de víctima; lo anterior, en oposición a lo establecido por el Derecho Internacional de los Derechos Humanos. Una investigación de carácter cualitativo aplicada a lo largo del proyecto permitió concluir que a pesar de la interpretación que concede cada tribunal al concepto de víctima, estos se esfuerzan por conceder una posición garantista a esta dentro del proceso penal establecido, que se acerca a lo instituido por la jurisprudencia de cortes regionales de derechos humanos. (grifo nosso);

\title{
A decisão pericial no âmbito da Previdência Social, de Maria da Penha
} Pereira de Melo e Ada Ávila Assunção. Resumo:

\begin{abstract}
A avaliação da capacidade laborativa dos segurados da Previdência Social que solicitam benefício por incapacidade, o auxílio-doença, é atribuição da Perícia Médica do Instituto Nacional do Seguro Social (INSS). Ter acesso ao benefício implica reconhecimento da existência de doença e de sua repercussão sobre a condição laborativa, na vigência de vínculo legal entre o segurado e a seguradora INSS. Este artigo apresenta resultados de pesquisa qualitativa desenvolvida com um grupo de treze médicos peritos. O trabalho desses peritos foi estudado utilizando-se categorias de análise da ergonomia e de técnicas de entrevistas e de autoconfrontação. O processo de decisão pericial foi estudado tomando-se como referência a noção de julgamento oriunda do Direito, tendo como marco teórico a Hermenêutica Jurídica, de Ronald Dworkin. Foram evidenciados conflitos na atividade médico-pericial, derivados da contraposição da demanda dos segurados com o ordenamento normativo da Previdência. Os resultados obtidos permitem afirmar que a avaliação pericial pressupõe a constituição de um código interpretativo constituído de princípios ordenadores de julgamento. Essa matriz interpretativa depende da forma peculiar de atuação e inserção social do profissional. Sendo assim, a decisão (ou julgamento) não pode ser pensada independentemente das influências políticas de uma prática social. (grifo nosso)
\end{abstract}

Desse modo, observa-se a importância de dar conhecimento e discussão à possibilidade de realização de pesquisas através da abordagem qualitativa nos campos de estudos do direito tanto no âmbito internacional como nacional.

\section{CONSIDERAÇÕES FINAIS}

Discutiu-se a possibilidade de realizar pesquisas no campo das ciências sociais aplicadas, sobretudo do Direito, através da metodologia de abordagem qualitativa utilizada nas pesquisas em ciências humanas.

Os objetos de estudo de ambas são conexos, pois trata-se do ser humano enquanto sujeito e objeto pesquisado como também dos fatos produzidos por este indivíduo ou sua coletividade, respectivamente. 
A pesquisa para produção de conhecimento era considerada até o século XIX apenas para as ciências naturais, sobre a qual era pacífico o uso de um método valendo-se do positivismo para interpretação dos resultados e os assuntos referentes aos seres humanos eram passíveis do estudo pela filosofia.

A partir da contribuição de Wilhelm Dilthey, as ciências humanas passaram a ser consideradas como aquelas responsáveis por analisar os comportamentos humanos e a esclarecer as estruturas do mundo no qual vive o homem. O referido filósofo e pedagogo alemão, descreveu as ciências humanas como sendo ciências do espírito, para as quais é difícil estabelecer um método por ser uma ciência passível de lidar com as mudanças naturais nos comportamentos humanos ao longo da vida, entretanto, pode adaptar-se o modelo das ciências naturais.

A pesquisa de abordagem qualitativa é largamente usada nas ciências humanas, sobretudo na área de Educação, visando produzir conhecimento através de uma amostra da realidade, com referência a fatores não desvelados antes das aplicações das técnicas possíveis nessa metodologia, tais como a aplicação de questionários e entrevistas.

O argumento para o uso dessa metodologia nos estudos no campo do Direito é o fato de não haver no Brasil um modelo a ser seguido pelas pesquisas na área jurídica, ficando a cargo do próprio pesquisador e de seu orientador a elaboração da metodologia a ser aplicada quanto ao objeto pesquisado.

Assim, se pretendemos um afastamento do positivismo com relação ao Direito, calibrando o tecnicismo da lei abstrata quando da aplicação ao caso concreto, humanizando as decisões jurídicas, essa metodologia por permitir que se desvele culturas, modos de pensar, necessidades, valores, poderá oferecer na produção do conhecimento uma orientação mais acertada quanto às reais necessidades de uma coletividade com referência a uma tutela jurídica, ou seja, dar o direito a quem é de direito.

Finalmente, os casos pesquisados junto às plataformas Scielo e CAPES quanto às pesquisas na área jurídica utilizando-se da pesquisa qualitativa ou de abordagem qualitativa confirmam que são poucas as produções acadêmicas no campo jurídico valendo-se dessa metodologia, demonstrando o seu desconhecimento e a necessidade da sua ampliação, sobretudo nas investigações de caráter interdisciplinar. 


\section{REFERÊNCIAS BIBLIOGRÁFICAS}

AGUIRRE BAZTÁN, A. Etnografia: metodología cualitativa en la investigación sociocultural. Barcelona: Marcombo, 1995.

AITH, F.M.A; ROTHBARTH, R.O. estatuto jurídico das águas no Brasil. Estudos Avançados, v. 29, p. 163-177. São Paulo: Instituto de Estudos Avançados da Universidade de São Paulo, 2012.

AMARAL, M.N.C.P. Introdução. In: Wilhelm Dilthey, Filosofia e Educação. Trad. Alfred Josef Keller e Maria Nazaré de Camargo Pacheco Amaral. São Paulo: EDUSP, 2010. BARDIN, L. Análise de Conteúdo. Trad. Luís Antero Reto e Augusto Pinheiro. 4 .ed. Lisboa: Edições 70, 2009.

BOGDAN, R., BIKLEN, S. Investigação qualitativa em educação: uma introdução à teoria e métodos. Porto: Porto Editora, 1991.

CARDOSO, C.F. História e paradigmas rivais. In: Ciro Flamarion Cardoso, Ronaldo Vainfas (orgs.) Domínios da História: ensaios de teoria e metodologia. 2a . ed. Rio de Janeiro: Campus, 2011, p.1-22.

CARVALHO, R. G. Wilhelm Dilthey e a atualidade da historicidade. Mneme - Revista de Humanidades, 13 (31), 2012.

DIAZ, D. R. V. El concepto de víctima al interior de tribunales penales internacional. Prolegómenos - Derechos y Valores, XVI (32). Universidad Autónoma del Estado de México, 2013, p. 87-103.

DILTHEY, W. Sobre a possibilidade de uma ciência pedagógica de validade universal. In: Wilhelm Dilthey, Filosofia e Educação. Trad. Alfred Josef Keller e Maria Nazaré de Camargo Pacheco Amaral. São Paulo: EDUSP, 2010. p.463-486.

ELlul, J. A Técnica e o Desafio do Século. Rio de Janeiro: Paz e Terra, 1968.

L'Empire du non sens: l'art et la société technicienne. Paris: PUF, 1980.

FAZENDA, I. C. A. Interdiciplinaridade-Transdisciplinaridade: visões culturais e epistemológicas e as condições de produção. Interdisciplinaridade, São Paulo, v.1, n. 2, out. 2012. Disponível em: <http://www.pucsp.br/gepi/downloads/REVISTA2-GEPIOUT12-2.pdf>. Acesso em: 11.03.2016.

FERRAZ JR., T. S.. A Ciência do Direito. São Paulo: Atlas, 1977.

FIGUERA VARGAS, S.; ARIZA LASCARRO, A. Derecho a la autodeterminación de los pueblos indígenas en el ordenamiento jurídico colombiano. Revista de Estudios Sociales, jul 2015, n. 53, p. 65-76.

GATTI, B. A. A construção da pesquisa em educação no Brasil. Brasília: Plano, 2002. 
GEWANSDZNAJDE, F.; MAZZOTTI, A. J. A.. O método nas ciências naturais e sociais. 2.ed.. São Paulo: Pioneira, 1999.

HERRERA FlORES, J. Teoria Crítica dos Direitos Humanos. Rio de Janeiro: Lumen Juris, 2009.

LYOTARD, J. F. A condição pós-Moderna. Trad. Ricardo Corrêa Barbosa. Rio de Janeiro: José Olympio, 2011.

LÜDKE, M., ANDRÉ, M.E.D. Pesquisa em educação: abordagens qualitativas. São Paulo: EPU, 1986.

MANZINI, E.J. Considerações sobre a elaboração de roteiro para entrevista semiestruturada. In: Maria Cristina Marquezine, Maria Amélia Almeida, Sadao Omote (orgs.). Colóquios sobre pesquisa em educação especial. Londrina: Eduel, 2003, p.11-25. Entrevista semiestruturada: análise de objetivos e de roteiros. In: Seminário internacional sobre pesquisa e estudos qualitativos, 2, 2004, Bauru: USC, 2004, p. 58-59. MELO, M. P. P.;

ASSUNÇÃO, A. A. A decisão pericial no âmbito da Previdência Social. PHYSIS: Rev. Saúde Coletiva, 13(2), p.105-127. Rio de Janeiro, 2003.

MONEBHURRUN, N.; VARELLA, M. D. O que é uma boa tese de doutorado em Direito? Uma análise a partir da própria percepção dos programas, Revista Brasileira de Políticas Públicas, v.3, n.2, 2013, p.424-443.

PAULILO, M. A. S. A pesquisa qualitativa e a história de vida. Serviço Social Revista, 1999, n. 2, v.1, p. 135-148. Disponível em: <http://www.ssrevista.uel.br/c_v2n1_pesquisa.htm>. Acesso em 10.02.2016.

SCOCUGLIA, J. B. C.. A hermenêutica de Wilheim Dilthey e a reflexão epistemológica nas ciências humanas contemporâneas. Sociedade e Estado, v. 17, n. 2, p. 249-281, jul./dez, Brasília, 2002.

STELZER, J.; GONÇALVES, E. N.. Princípio da eficiência econômico-social no direito brasileiro: a tomada de decisão normativo-judicial. Sequência, n. 68, p. 261-290. Florianópolis, 2014. Disponível em: <Doi: http://dx.doi.org/10.5007/2177-7055.2013v35n68p261>. Acesso em 03.abril.2016.

TRIVIÑOS, A. N. S. Introdução à pesquisa em ciências sociais: a pesquisa qualitativa em educação. São Paulo: Atlas, 1987.

VARGAS DÍAZ, D. R. El concepto de víctima al interior de tribunales penales internacionales. Prolegómenos, jul 2013, v. 16, n. 32, p.87-103.

ZAMANI-ALAVIJEH, F. et al. Motorcyclists' reactions to safety helmet law: a qualitative study. BMC Public Health, 2009, v.9, p.393-393. 